\title{
Kidney function and DDT value comparison in pre- and post-spray plasma of the spray personnel in Northern Uganda in 2008
}

\author{
G.S. BIMENYA ${ }^{1 *}$, M. HABARULEMA ${ }^{2}$, J.P. OKOT ${ }^{2}$, A.L. OKWI ${ }^{1}$ and \\ Myers LUGEMWA ${ }^{3}$ \\ ${ }^{1}$ Pathology Department, School of Biomedical Sciences, College of Health Sciences. Makerere University, \\ P.O.Box 7072 Kampala, Uganda. \\ ${ }^{2}$ Mulago Hospital Complex, P.O.Box 7051 Kampala, Uganda. \\ ${ }^{3}$ Malaria Control Program. 1, Kampala, Uganda. \\ * Corresponding author, E-mail: gsbimenya@med.mak.ac.ug
}

\begin{abstract}
In-door residual spray of the insecticide dichlorodiphenyltrichloroethane was re-introduced for malaria control in Uganda and there was need to assess its health impact among the spray personnel. To compare kidney function and the insecticide values in pre-and post-spray plasma of spray persons in northern Uganda, heparinized blood samples were analyzed in the Department of Pathology, College of Health Sciences, Makerere University, for the insecticide and its main metabolite dichlorodiphenylethane using enzyme linked immunosorbent assay kits from Abraxis ${ }^{\mathrm{TM}}$ (USA). Urea and creatinine were analyzed on Konelab $^{\mathrm{TM}}$ (Finland) chemistry analyzer. The 109 pre-spray samples had mean (SD) values of the insecticide/metabolite of 63 (19) while the 96 post-spray samples had mean (SD) of 77 (26) ppb. The 96 prespray samples had urea concentration mean (SD) of $3.50(1.11) \mathrm{mmol} / \mathrm{L}$ while 119 post-spray samples had mean (SD) of $3.86(1.07) \mathrm{mmol} / \mathrm{L}$. The pre-spray samples had creatinine mean (SD) of $65.58(12.05) \mu \mathrm{mol} / \mathrm{L}$ whereas the post-spray had mean (SD) of $79.82(14.81) \mu \mathrm{mol} / \mathrm{L}$. The post-spray urea and creatinine values were higher than the pre-spray $(\mathrm{p}<0.05)$ despite the fact that all were within reference ranges. The insecticide had no deleterious effects on kidney function. Therefore, dichlorodiphenyltrichloroethane can be used safely for in-door residual spray in control of malaria disease.

(C) 2009 International Formulae Group. All rights reserved.
\end{abstract}

Keywords: Malaria, mosquito, control, insecticide, urea, creatinine.

\section{INTRODUCTION}

Despite collective health service efforts to control malaria, the disease still remains too heavy a burden for Uganda accounting for $26 \%$ of the national disease burden and responsible for $33 \%$ of outpatient attendance in addition to the $25 \%$ of hospital admissions of which $20 \%$ are child admissions. The death toll is estimated at 320 daily, and mostly of pregnant women and children (Rwakimari, 2008).

Although $93 \%$ of Uganda's population is at risk from malaria, the districts of Apac,
Amolatar, Dokolo and Oyam in Lango subregion in Northern Uganda are the most vulnerable to malaria in the whole country and possibly in the whole world: they lie within the tropical Kyoga Lake basin which provides an ideal breeding ground for mosquitoes; the average rate of malaria is at 420 per 100,000 people against the national rate of 260 that is still much higher than the global rate of only 90 per 100,000 people (Otala, 2008). The Health Ministry spends on malaria per year over $\$ 600 \mathrm{M}$ on curative services without making a big dent to the burden (Zaramba, 
2008). So, in a preventive strategic change, the Ministry of Health launched in-door residual spray (IRS) with the World Health Organization (WHO) approved insecticides including dichlodiphenyltrichloroethane (DDT) to cover the whole country starting with Apac and Oyam in February 2008. However, only the two districts were sprayed with DDT because the High Court of Uganda ordered the stay of the spray, pending a ruling on the IRS use of DDT in Northern Uganda. The litigants included various organic farmers of coffee and tobacco companies (Muhumuza, 2008).

Considering the use of DDT in malaria control, it was advised that any country in the world intending to use DDT or any other insecticide in IRS malaria control ensures that the program is well controlled with scientific and medical over sight (Bate et al., 2004). Moreover, in East Africa, it was observed that research necessary to make informed decisions on malaria control policy was lacking and that there was a need to educate malaria and insecticide specialists on the human health impacts of insecticides used for vector control, including DDT (Biscoe et al., 2005). So, in Uganda now, the government policy is that the application of the insecticide DDT should follow a scheme that allows the assessment of its accumulation in the environment and evaluation of its possible deleterious effects on man and the food chain (Zaramba, 2008). This study, therefore, compared the DDT values found in the plasma of spray persons before the application of DDT with the values found in plasma six months after the one round of DDT spray in the districts of Apac and Oyam of Lango subregion in Northern Uganda.

Although DDT/DDE is a reported possible carcinogen in animal models, no such effects have been reported in people even with excessive exposure to DDT including Ugandans who worked with DDT(De Zulueta et al., 1961) in malaria eradication project of $1959 / 60$ in Kanungu District of South Western Uganda (Bimenya et al., 2007). However, controversy exists concerning the kidney: whereas Hayes and Laws (1991) reported no indication of renal damage in people accidentally poisoned by DDT or in workers heavily exposed to it, yet, Niyazi et al. (2004) reported acute oliguric renal failure following unintentional DDT ingestion which, among others affected urea and creatinine excretion.

This study, therefore, set out to establish the pre-spray plasma levels of DDT with its metabolite, dichlorodiphenylethane (DDE) against the baseline kidney function in DDT sprayers in Northern Uganda, and to review them six months after the stayed spray of DDT in 2008.

The study areas included Apac and Oyam districts of Lango subregion of Northern Uganda hereafter referred to in this paper as Northern Uganda (Figure 1).

A clinician from Ministry of Health Malaria Control Program did the field examinations of the DDT spray persons and, after obtaining informed and signed consent, collected heparinized blood samples and spot urine under health unit setting. The specimens were cooled and delivered to the Department of Pathology, College of Health Sciences, Makerere University, for analysis for DDT/DDE in plasma and for biochemical screening markers of kidney disease (urea and creatinine). This was repeated in a review six months after the last contact with DDT in IRS program in Northern Uganda, 2008.

The DDT/DDE in plasma was extracted with methanol and analyzed using enzyme linked immunosorbent assay (ELISA) kits supplied by Abraxis, USA. The samples were processed according to the manufacturer's standard operating procedures and quality assurance instructions: during the reactions, color that was inversely proportional to the concentration of DDE, the principle derivative of DDT in the sample, developed; its intensity was translated and converted into concentration by comparing with that produced by the standards and controls supplied with the DDT reagent kits; the concentrations were read at 450 and 630 $\mathrm{nm}$ and printed automatically by the ELISA plate reader - the Stat $\mathrm{Fax}^{\mathrm{Reg}} 303$ Plus (Awareness Technology, Inc, Palm City, FL 1987-2001).

The clinical history and the physical examination on recruitment of the participants were all normal (Bimenya et al., 2009a) and so were their reviews six months after the last contact with DDT (Bimenya et al., 2009b).

In assaying for biochemical markers of kidney disease (urea and creatinine), 
automated routine clinical chemistry methods, on Konelab ${ }^{\mathrm{TM}}$ (Finland) chemistry analyzer, were used. Heparinized plasma samples were analyzed for the concentration values of urea (Sampson et al., 1972) and plasma creatinine (Fabiny and Erlighausen, 1971) in both preand post-spray samples.

The pre-spray plasma urea concentration was reported previously (Bimenya et al., 2009a) as mean (SD) of 3.50 (1.11) $\mathrm{mmol} / \mathrm{L}$ in 95 plasma samples whereas the post-spray concentration was also previously reported (Bimenya et al., 2009b) as mean (SD) of $3.86(1.07) \mathrm{mmol} / \mathrm{L}$ in 119 samples

In the current study, the chemistry analytical results were retrieved at 2 levels, each with its particular concerns as follows:the primary level displayed the main toxicological measure of interest: the DDT/DDE concentration in plasma samples of pre- and post-spray participants of the indoor residual spray of DDT in Northern Uganda; the secondary level displayed the concentration values of selected biochemical markers of kidney disease in the plasma of the same group participants before and six months after IRS of DDT in Northern Uganda in the year 2008 .

The objectives of these researches are to compare the concentration of DDT/DDE in plasma samples from the spray team before and six months after the IRS of DDT in Northern Uganda, 2008 and also to compare plasma levels of biochemical markers of kidney disease in blood from the spray team before and six months after exposure to DDT in order to compare the background levels of DDT with the concentration increase after DDT IRS application and to discern the effects the chemical has on kidney function.

\section{MATERIALS AND METHODS}

The study areas included Apac (3) and Oyam (4) districts of Lango subregion of Northern Uganda hereafter referred to in this paper as Northern Uganda (Figure 1).

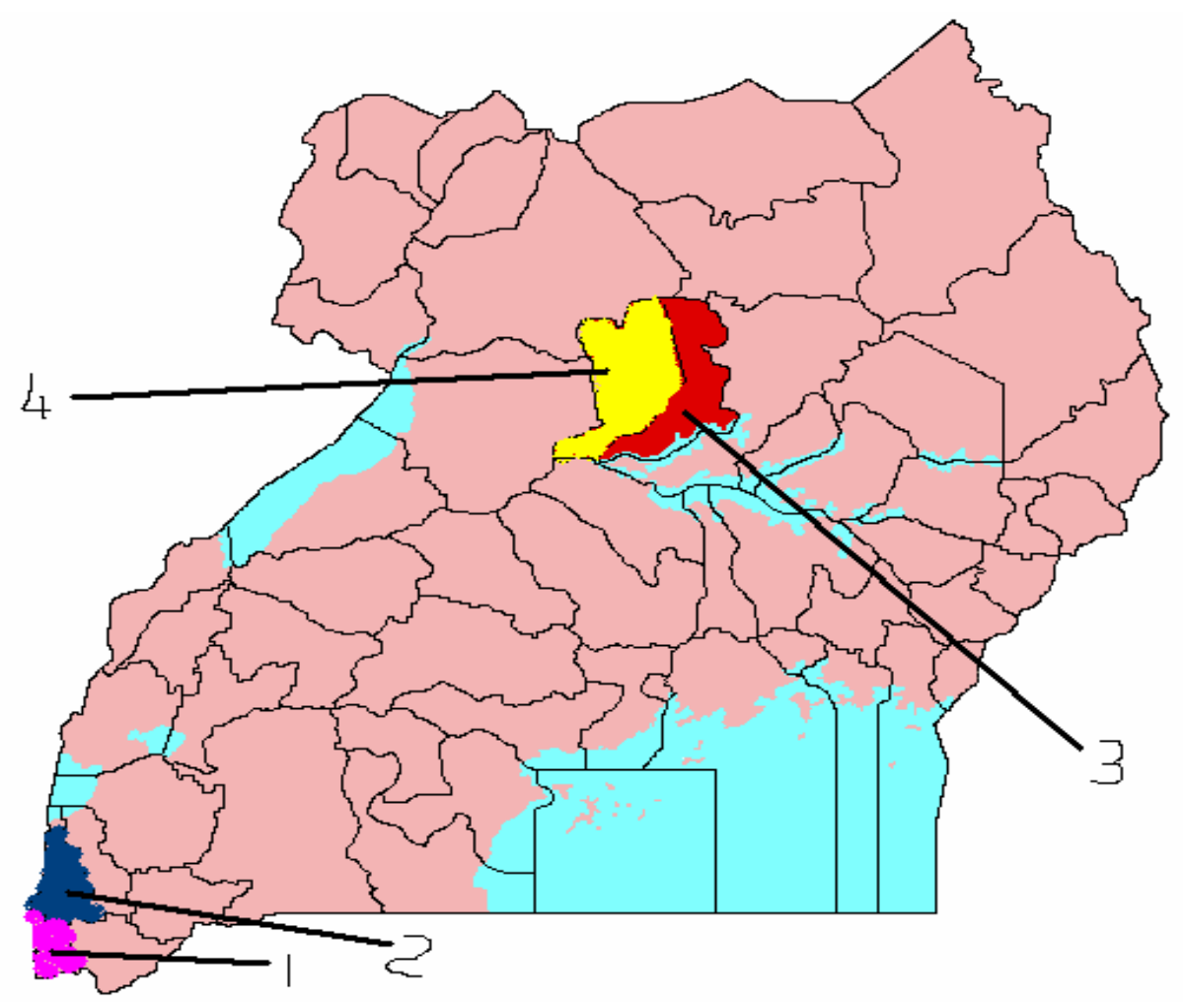

Figure 1: The Districts of Uganda referred to with respect to DDT use. (1=Kisoro, 2=Kanungu, $3=$ Apac, 4=Oyam). 


\section{Clinical History and Physical Examination}

The records of the clinical history and the physical examination done before and six months after DDT spray were retrieved for qualitatively comparative scrutiny.

\section{Plasma concentration of DDT/DDE}

The pre-spray values of DDT/DDE were retrieved as mean (SD) of 63 (19) in 109 plasma samples whereas in 96 post-spray samples the mean (SD) of DDE was 77 (26) ppb. Their distributions were also recovered.

\section{Plasma concentration of Urea}

The pre-spray plasma urea concentration was recovered as mean (SD) of 3.50 (1.11) $\mathrm{mmol} / \mathrm{L}$ in 96 plasma samples whereas the post-spray concentration was also restituted as mean (SD) of $3.86(1.07) \mathrm{mmol} / \mathrm{L}$ in 119 samples. The distribution was also restored.

\section{The plasma creatinine}

The creatinine concentration in the 96 pre-spray samples was revisited as mean (SD) of $65.58(12.05) \mu \mathrm{mol} / \mathrm{L}$ whereas the postspray concentration was retrieved in 119 samples as mean (SD) of 79.82 (14.81) $\mu \mathrm{mol} / \mathrm{L}$. Each distribution was also recalled. These results retrieved were compared to document any associated longitudinally abnormal changes.

\section{RESULTS}

The clinical history and physical examination

There was no record of adverse effects especially on the thyroids, the testes, and the liver. In particular, there was no adverse effects recorded on the urinary system.

\section{The distribution of DDT/DDE concentration}

The distribution patterns of DDT/DDE concentration in the pre- and post-spray plasma were compared for the first time in figure 2 .

The distribution patterns of DDT/DDE concentration were similar in both pre- and post-spray plasma; there was no single specimen void of DDT/DDE; in both, the highest concentration was $50 \mathrm{ppb}$ above the highest respective value in urine (not shown); whereas the plasma concentration of DDE mean (SD) was 63 (19) and lower than respective values of post-spray plasma at 77 (26) $\mathrm{ppb}$, on average, there was $15 \mathrm{ppb}$ increase in DDT/DDE concentration in the post-spray samples.

\section{The distribution of plasma Urea}

The distribution patterns of urea concentration in the pre-spray and post-spray plasma were compared for the first time in figure 3 . The distribution patterns were similar: they both fell below the upper reference limit of 6.4 $\mathrm{mmol} / \mathrm{L}$; although the post-spray plasma exhibited higher plasma urea mean (SD) concentration of 3.86 (1.07) $\mathrm{mmol} / \mathrm{L}$ compared to the respective values of pre-spray plasma at $3.50(1.11) \mathrm{mmol} / \mathrm{L}$ both values were within the reference range and no kidney disease was detected.

\section{The plasma creatinine}

The distribution patterns of the concentrations of creatinine in the pre-and post-spray plasma were compared for the first time in figure 4.

The distribution patterns of creatinine concentration in the pre-spray and post-spray plasma were similar: both were below the upper limit of the reference range at 140 $\mu \mathrm{mol} / \mathrm{L}$; they were expectedly leptokurtic and positively skewed; both indicated normally excreting kidneys. Although the post-spray plasma had higher creatinine concentration mean (SD) of $79.82(14.81) \mu \mathrm{mol} / \mathrm{L}$ than the pre-spray plasma at $65.58(12.05) \mu \mathrm{mol} / \mathrm{L}$, none detected any kidney disease. The postspray distribution was unusually nearGaussian, indicating possible alteration in protein metabolism.

In summary, Table 1 compared the distribution patterns of the respective analytes in 96 pre-spray plasma samples with those in 119 post-spray samples.

There were increases in the post-spray samples on average as follows: DDE at 15 $\mathrm{ppb}$, urea of $0.36 \mathrm{mmol} / \mathrm{L}$ and creatinine at $14.24 \mu \mathrm{mol} / \mathrm{L}$; all were within the respective (or inducible) reference ranges and none showed any deleterious effects on the study participants. 
G. S. BIMENYA et al. / Int. J. Biol. Chem. Sci. 3(5): 948-956, 2009

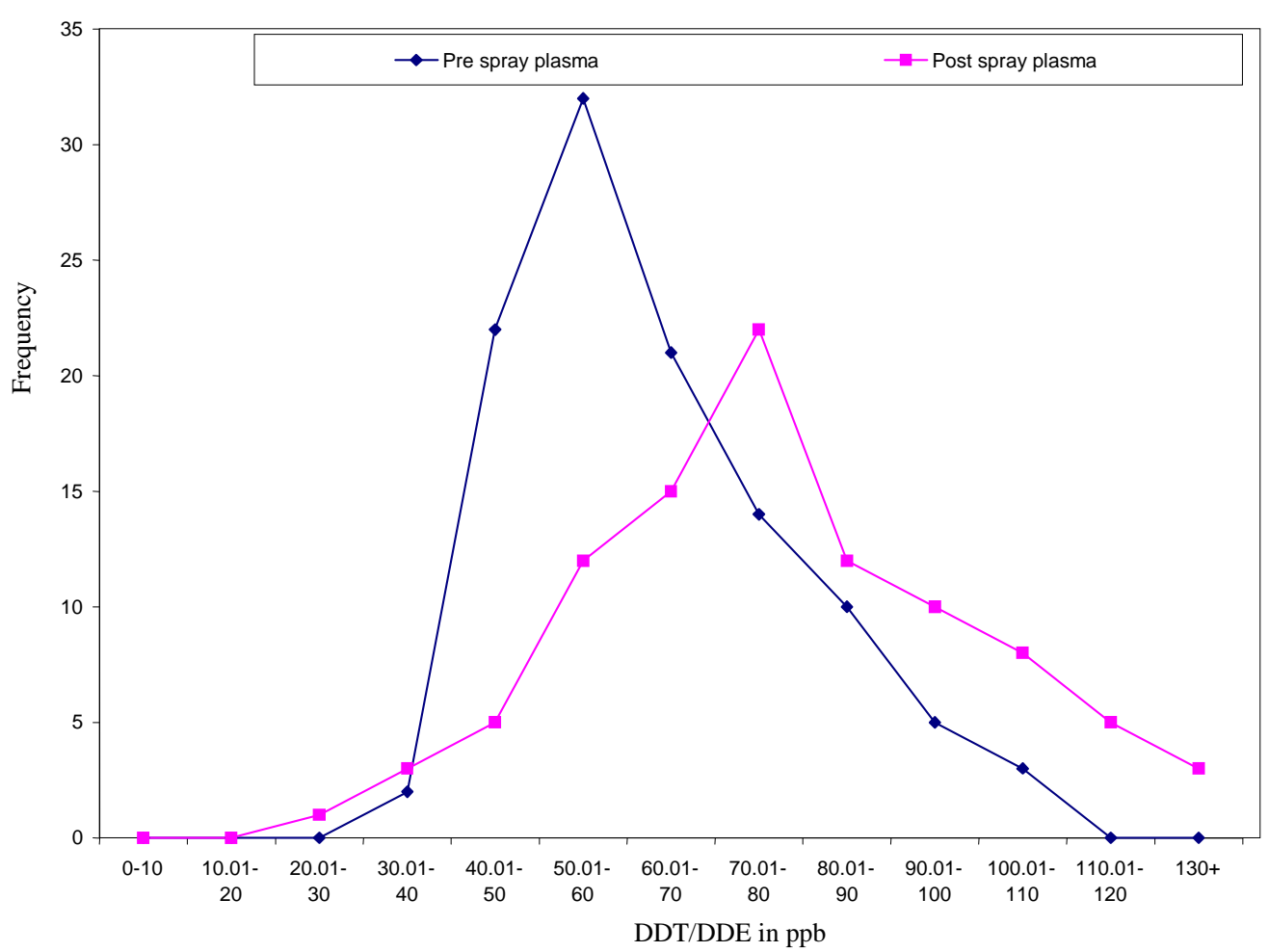

Figure 2: The DDT/DDE distribution patterns in the pre- and post-spray plasma.

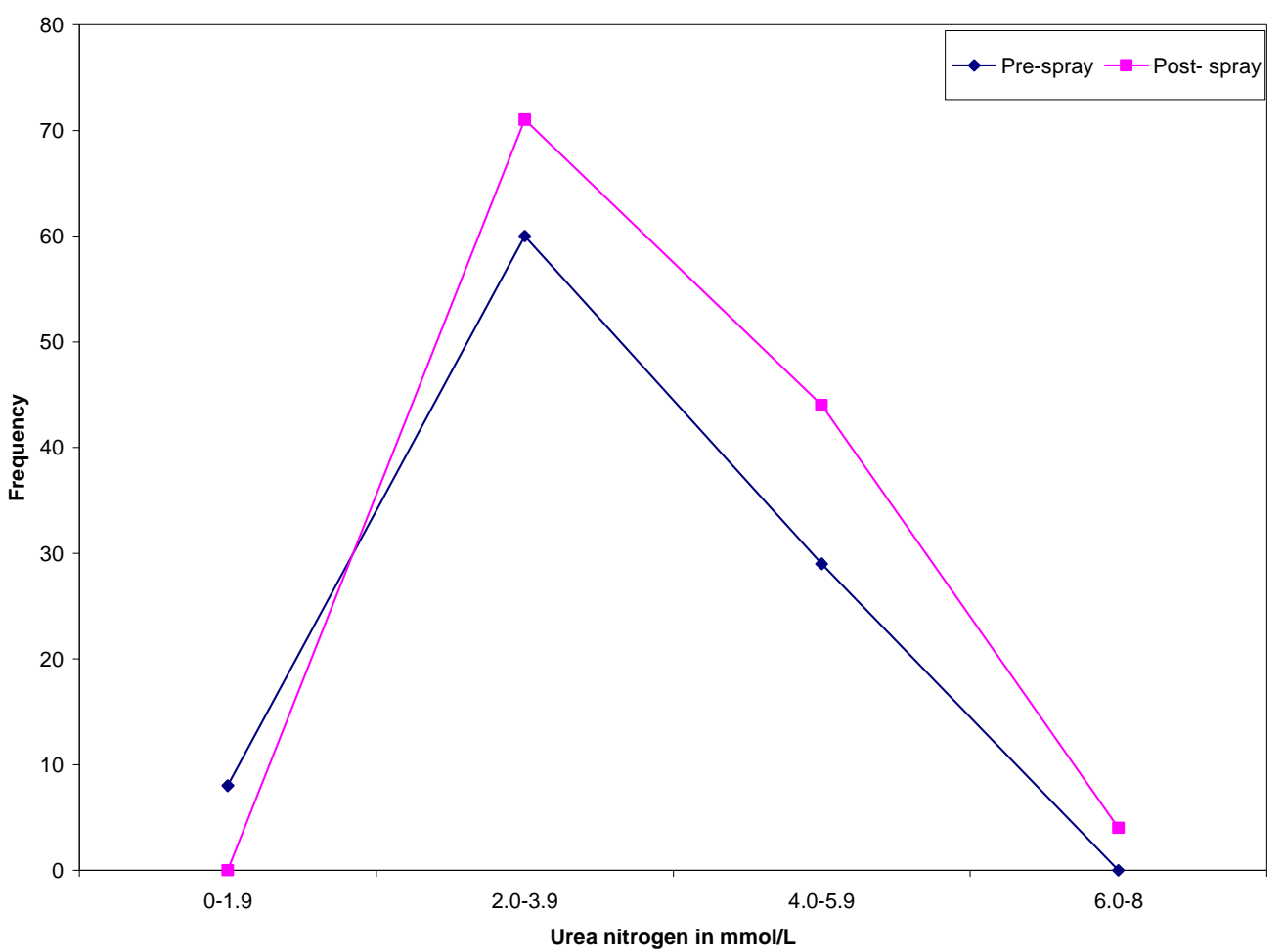

Figure 3: The Urea distribution patterns in the pre- and post-spray plasma. 


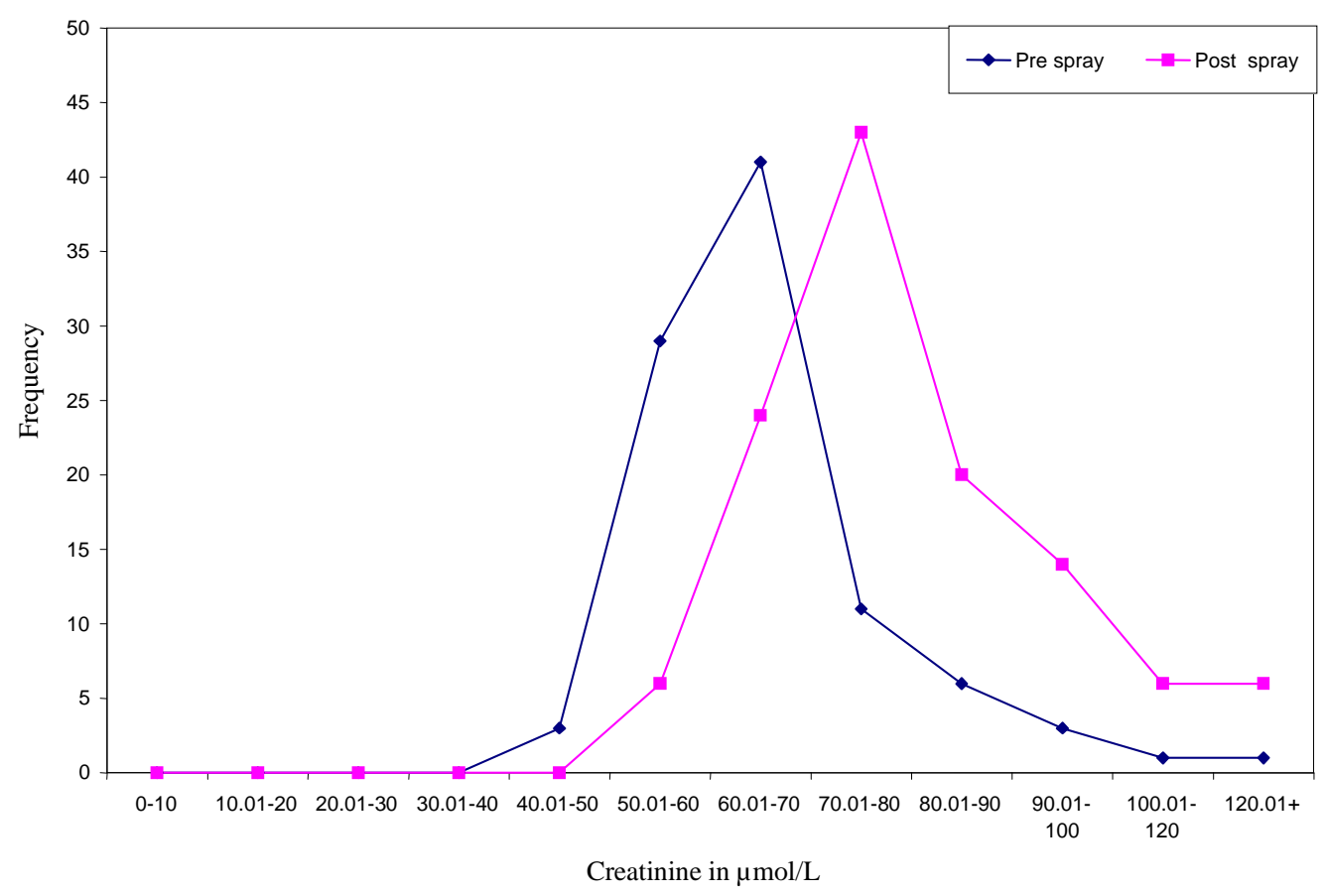

Figure 4: The creatinine distribution patterns in the pre-and in the post-spray plasma.

Table 1: Summary Statistics (2-tailed t-test) of chemical analyses in pre-spray (1) and in post-spray (2) plasma of DDT sprayers in Northern Uganda, 2008.

\begin{tabular}{|c|c|c|c|c|c|}
\hline Marker & $\begin{array}{ll}\begin{array}{l}\text { Ref. } \\
\text { units }\end{array} & \text { Range } \\
\end{array}$ & Sample Class & $\mathbf{N}$ & Mean(SD) & $\begin{array}{l}\text { p level of } \\
\text { significance }\end{array}$ \\
\hline \multirow{4}{*}{ DDT } & \multirow{4}{*}{$\mathrm{ppb}$} & 1 & 96 & $62.92(17.11)$ & \multirow{3}{*}{$\mathrm{p}<0.05$} \\
\hline & & & & & \\
\hline & & 2 & 119 & 77.15 (27.64) & \\
\hline & & 1 & 96 & $3.50(1.10)$ & \multirow{3}{*}{$\mathrm{p}<0.05$} \\
\hline \multirow[t]{2}{*}{ Urea } & $2.5-8.0$ & & & & \\
\hline & $\mathrm{mmol} / \mathrm{L}$ & 2 & 119 & $3.86(1.07)$ & \\
\hline \multirow[b]{2}{*}{ Creatinine } & & 1 & 96 & $65.58(11.00)$ & \multirow[b]{2}{*}{$\mathrm{p}<0.05$} \\
\hline & $\begin{array}{l}70-140 \\
\mu \mathrm{mol} / \mathrm{L}\end{array}$ & 2 & 119 & $79.82(14.81)$ & \\
\hline
\end{tabular}

\section{DISCUSSION}

These results confirmed the ubiquity of DDT/DDE. They punctuated the persistence of DDT in the environment. They indicated relative safety of small amounts of DDT/DDE in the human body thereby alleviating fears of acute toxicity when applied at IRS doses. These findings also dispelled fears of long term toxicity of DDT in small quantities used in IRS. Above all, the results dissipated fears of kidney dysfunction putatively associated with application of small IRS doses. The inferences from this study tend to encourage programs that support IRS of DDT in malaria control.

Concerning the hot debate on the use of chemicals such as DDT for malaria control, the Global Conservation Organization whose 
goal is to stop the degradation of the planet's natural environment and to build a future in which humans live in harmony with nature quoted the World Health Organization reminiscence of 2002 (WHO, 2002) that "The exposure data sets that exist are primarily for various environmental media (air, food water and soil) rather than the most relevant internal exposure (blood, tissue) . Limited exceptions are human breast milk, and adipose tissue samples. Worldwide, in spite of large expenditures of money, time and effort, comparable data sets for assessing exposure for EDCs for humans or wildlife are not available. Such information is essential to adequately evaluate exposure/response relationships to produce credible risk assessments" (WWF, 2004). This study provides the evidence-based evaluation to produce the badly needed credible risk assessments of IRS usage of DDT in malaria control programs.

While studying the toxicity of chemicals, it is recommended in toxicology to go beyond the plasma concentration of the poison. Specifically for DDT, Gosselin et al. (1984) recommended strongly that dedicated biochemical analyses be performed to detect liver and kidney dysfunction and that, desirably, blood sugar and sugar tolerance levels be determined. The results of such dedicated investigations or their equivalents on kidney function are discussed hereunder in the context of the toxicological findings among participants in IRS of DDT in malaria control of Northern Uganda, 2008.

In toxicological analysis, this work found that before spraying DDT in Northern Uganda, the apparently healthy spray persons, thought to be DDT-naïve, had DDT/DDE in their blood to the average concentration of 62 $\mathrm{ppb}$. Though these values are higher, yet they agree with the average of $9.70 \mathrm{ppb}$ of DDT/DDE found in plasma samples from Nyarusiza people of Kisoro District in South Western Uganda (Figure 1) where DDT has never been officially applied (Bimenya et al.,
2007). Moreover, these results agreed with the Global Conservation Organization's study that in June 2004 analyzed blood samples from 14 healthy European ministers from 13 countries of the EU including those from UK, Sweden, Spain, Italy, Denmark and France and found that DDT/DDE was in each one of the samples, the highest concentration being $3300 \mathrm{pg} / \mathrm{g}$ of the DDT metabolite, pp|-DDE (WWF, 2004).

Furthermore, the background results in this work corroborated Turusov et al. (2002) who asserted that on this planet now, there is not a single living organism that does not contain DDT. These results confirmed that people live apparently healthy with stores of DDT/DDE in their bodies, meaning that DDT/DDE is relatively harmless to human beings. These results showed an average increase of only $15 \mathrm{ppb}$ DDE in plasma of sprayers six months after the last contact with DDT, meaning inter alia that the recommended protective measures (WHO/CDS/WHOPES/GCDPP/2000.3) are effective and that they were adhered to by the spray team.

The biomedical results in this work showed healthy kidney function in the sprayers before and after DDT application against malaria in 2008. The concentrations of plasma urea and of plasma creatinine fell within the reference ranges for both analyses. This meant that chronic exposures to some DDT levels encountered in this work had no deleterious effects on kidney function as evidenced by the levels of urea and of creatinine in the plasma of the participants along the plasma levels of DDT/DDE before the IRS. The findings also meant that at the IRS dose applied in Northern Uganda, DDT had no acute toxicity on kidney function as exhibited by the normal levels of urea and of creatinine in the post-spray samples, all buttressed by good clinical history and clinical examination results. These findings agree with those reported by Hayes and Laws (1991) that there was no indication of renal 
damage in people accidentally poisoned by DDT or in workers heavily exposed to it. This means that the environmental doses found in Northern Uganda coupled with the small IRS doses added in IRS of malaria control program did not have either chronic or acute toxicity on kidney function.

Our results of the biochemical markers of disease uniquely and opportunely filled the gap that had been regrettably observed by WHO (2002). This science absolved DDT of its alleged toxicity to man at the concentrations obtained in IRS programs. Our spray participants protected themselves while at work during the day, but stayed unprotected like any other inhabitant in the IRS protected homes. For a long time now, there have been lots of arguments without justification against application of DDT in malaria control. These results serendipitously obtained abreast six months of only one round of DDT spray in Northern Uganda in 2008 coupled with those longitudinal study results previously reported from the districts of Kisoro and Kanungu of Southern Uganda (Figure 1) in 2005 (Bimenya et al., 2007) did serve to provide the risk assessment badly needed by all well wishers of harmonious life of humans with nature. This is because, unlike other insecticides, DDT does not protect man by only killing the mosquitoes; it primarily repels them at a distance, irritates them at proximity and only kills them as a last resort on contact, even then through absorption. We still need DDT to protect the Uganda people against the Anopheles mosquito in malaria control programs as was successifully done in the now Kanungu District of Southern Uganda in $1959 / 60$ and reported the following year by De Zulueta et al. (1961). Such use of DDT will avert malaria calamities likely to be associated with the Global Climate Change.

\section{ACKNOWLEDGEMENTS}

The authors wish to acknowledge the financial assistance from the Ministry of
Health through International Research Triangle Institute.

\section{REFERENCES}

Bate R, Tren R, Urbach J, Zambone J. 2004. Consideration for the use of DDT in malaria control. American Enterprise Institute for public policy research File://C:\Documents and Settings\Admin My Documents\AEI-Short PublicationsConsi.... AEI Print index No.17493.

Bimenya GS, Byarugaba W, Byarugaba B, Lugemwa M, Okwi AL. 2007. The case for spraying with DDT as a strategy against malaria. Malaria Control and Prevention, Forum for Health \& Nutrition, Uganda National Academy of Sciences; 83-96.

Bimenya G.S, Habarulema M, Okot JP, Okwi AL, Lugemwa M. 2009a. Plasma levels of DDT/DDE and kidney function in malaria control personnel prior to DDT in-door residual spray in Northern Uganda, 2008 (Manuscript submitted to African Health Sciences, 2009).

Bimenya GS, Habarulema M, Okot JP, Okwi AL, Lugemwa M. 2009b. Plasma levels of DDT/DDE and kidney function in malaria control personnel six months after DDT in-door residual spray in Northern Uganda, 2008 (Manuscript submitted to Malawi Medical Journal) .

Biscoe ML, Mutero CM, Kramer RA. 2005. DDT use for malaria control in East and Southern Africa: persipectives, politics and policy. Epidemiology, 16(5): S131S132.

De Zulueta J, Kafuko GW, Cullen JR, Pedersen CK. 1961. The results of the first year of malaria eradication project in Northern Kigezi. East Afr. Med. J., 38: 126

Fabiny DL, Erlinghausen G. 1971. Automated reaction rate method for determination of serum creatinine with the CentrifiChem. Clin. Chem., 17: 696700 . 
Gosselin RE, Smith RP, Hodge HC. 1984. Clinical Toxicology of Commercial Products. Williams, Wilkins: Baltimore; 134-136.

Hayes WJ, Laws ER. 1991. Handbook of Pesticide Toxicology. Academic Press, Inc.; 743-780.

Muhumuza R. 2008. Court halts DDT spray in Northern Uganda Sunday Monitor June $3^{\text {rd }}$, 2008. http//www.monito.co.ug/ artman/publish/news/court_halts_DDT_s pray_in_Northern Uganda.

Niyazi OD, Karcioglu O, Topakoglu H, Fowler JR. 2004. Toxicity following unintentional DDT ingestion. J. Toxicol. Clin. Toxicol., 42(3): 299-303.

Otala E. 2008. Malaria on the Rise in Lango Oyam. IRIN 19th November, 2008 http://www.irinnews.org/Report.aspx?Re portId $=81558$

Rwakimari JB. 2008. The scaling up of malaria control in Uganda with special emphasis on IRS and DDT : Inaugulation of multisectoral committee monitoring IRS to control malaria , Workshop held at Imperial Hotel Kampala 7-8 April, 2008.
Sampson EJ,Baired MA,Burtis CA,Overton JB,Scott CD, 1972. Enzymatic kinetic rate and end point analyses of substrate by use of a GeMSAEC Fast Analyzer. Clin. Chem., 18: 829-840.

Turusov V, Rakittsky V, and Tomatis L 2002. Dichlorodiphenyl trichloethane (DDT): Ubiquity. Persistance, and Risks. Environmental Health Perspective, 110(2): 125-128.

WHO, 2002 as quoted by reference WWW 2004 on page WHO/CDS/WHOPES/ GCDPP/2000.3: Manual for indoor residual spraying.

WWF, 2004. Bad Blood? A survey of chemicals in the blood of European ministers, WWWDetox Campaign 200.

Zaramba S. 2008. Terms of reference for the multisectoral committee for monitoring IRS and DDT to control malaria: Inaugulation of multisectoral committee monitoring IRS to control malaria, Workshop held at Imperial Hotel Kampala 7-8 April, 2008. 